\title{
Demand for Improved Public Transport Services in the UAE: A Contingent Valuation Study in Dubai
}

\author{
Genanew Bekele Worku' \\ ${ }^{1}$ Economics and Statistics Department, College of Business Administration, University of Dubai, Dubai, UAE \\ Correspondence: Genanew Bekele Worku, Economics and Statistics Department, College of Business \\ Administration, University of Dubai, P.O. Box 14143, Dubai, UAE. Tel: 971-4-207-2623. E-mail: \\ gbekele@ud.ac.ae or gensich@yahoo.com
}

\author{
Received: February 28, 2013 Accepted: March 29, 2013 Online Published: April 27, 2013 \\ doi:10.5539/ijbm.v8n10p108 URL: http://dx.doi.org/10.5539/ijbm.v8n10p108
}

\begin{abstract}
Service quality, being an integral part of urban growth, has been a subject of interest to city transport planners. The provision of better quality public transport service is a challenge in the United Arab Emirates, as this country strives to meet the transport requirements fundamental to sustain the investment and economic as well as urban population growth exhibited over the last few years. United Arab Emirates Government intervention strategies include increasing share of public transportation and decreasing transport by private vehicles through bettering bus service delivery. Such shift of demand for public service requires not only understanding of people's willingness to use and pay for improved public transport services but also market incentives to pull-down personal vehicle ownership demand into public transport services. This study examines the willingness of United Arab Emirates residents to use and pay for improved public transport services. A contingent valuation survey is conducted on 852 representative sample of cross section of United Arab Emirates residents. Probit and Ordered logit models are used to analyze the survey data. The study has generated results with significant ramifications for policy. It suggests that there is the knowledge that residents, in general, are willing to use and pay higher fees for using public bus provided its service quality is improved. This has to provide reassurance to the Roads and Transport Authority who may be interested about the potential demand for improved public bus service. In order for the United Arab Emirates Government to increase the share of public transportation and decrease transport by private vehicles, effort will have to continue to improve the public bus service quality. In particular, marketing of such improved service will have to consider the residents' socioeconomic and demographic as well as some travel attributes.
\end{abstract}

Keywords: willingness to pay, public transport, contingent valuation, probit model, ordered logit model, UAE

\section{Introduction}

Growth in urban centers requires strategies (e.g. transportation planning) which ensure that such growth should not adversely affect the inhabitants' quality of life (cf. Murray and Wu, 2003). Service quality, being an integral part of urban growth, has been a subject of interest to city transport planners (cf. Zheng et al., 2011; Elboli and Mazzula, 2008; and Phanikummar and Maitra, 2006). In the United Arab Emirates (UAE), as the case is elsewhere, quality public transport service delivery is the topic of greatest importance for governments and city planners. The provision of better quality public transport service is a challenge in the United Arab Emirates, as it strives to meet the transport requirements fundamental to sustain the investment and economic as well as urban population growth exhibited over the last few years. In this regard, the UAE vision (cf. Dubai Strategic Plan, DSP 2015) (Note 1) is to increase the share of public transportation and decreasing transport by private vehicles, and hence contribute towards mitigating air and sound pollution as well as traffic congestion. Such vision (as the case is in some developed countries) can be met, however, it requires market incentives to pull-down personal vehicle ownership demand into public transport services (such as bus and/or metro).

Despite UAE's vision to increase the share of public transportation, personal vehicle ownership trend does not show a decline over the years among the UAE residents. The public transport service could not attract the mid and high income earners - who would do well to use the public bus and relieve traffic congestion and accident that has recently become a major problem in Dubai and the UAE, thereby contributing towards air and sound pollution. The number of passengers using public transport held steady in Dubai over the past years, rising by 
only 4 percent between 2005 and 2008. As stated in 'Dubai at random', 2008, "...the bus service in Dubai is unacceptable, forcing everyone to buy a car". On the other hand, some buses are running at "low capacity" across the emirates.

Currently, such services have low arrival and departure reliability (long waiting time), low travel speed, low frequency, and discomfort (at times crowding inside buses). These travel attributes need to be changed to bring improvement in the public transport services which is often associated with increase in passenger's fee. The execution of UAE's transportation vision should focus on the demand as opposed to the supply side thereby adjusting pricing mechanisms and regulatory measures. Pricing of public service is the key component of an appropriate incentive for balanced and coordinated quality public transport service. For demand-driven improvements in the existing public transport service and understanding of people's willingness to pay for improved public transport services, it is necessary to evaluate passengers benefit and understand the values passengers place on the different travel attributes. Moreover, the need to fill the gap of information on the demand side for policy purposes is timely. The objective of this study is, therefore, to examine passengers' willingness to use and pay for improved public transport services. Specifically, it addresses the following research challenges:

- Are passengers willing to use an improved public transport service?

- What factors [or travel attributes such as arrival and departure reliability, travel speed, frequency, and discomfort determine residents' willingness to use (WTU) an improved public transport service?

- How much are residents willing to pay (per trip) for an improved public bus transport service?

- What factors [or travel attributes such as arrival and departure reliability, travel speed, frequency, and discomfort] determine residents' willingness to pay (WTP) for an improved public transport service?

A contingent valuation (CV) survey is conducted on a representative sample of a cross section of UAE's residents in terms of income, nationality, gender, and other transport attributes. This CV primary survey elicited passengers demand for improved public transport service by finding out whether or not they are willing to use and what amount they would be willing to pay for the change in the improvement. From such survey data, not only that we generated passengers willingness to use but also their maximum willingness to pay, which will be used to understand the demand for public transport. Moreover, we will also use it to conduct valuation process of the public transport service without having to estimate the actual demand curve. Probit and Ordered logit models are used to analyze the survey data.

It is believed that this study will help decision makers in developing a win-win-win strategy in achieving economic growth, improved public transport service, and mitigating pollution. It will also help to verify the possibility for wider applicability of planned public transport service as a potential policy option to improve the environmental condition of urban areas in the UAE. This study can also be an addition to the very limited information available in literature about willingness to pay for improved public transport service in the Gulf Cooperation Council (GCC) such as UAE. Despite the application of CV method elsewhere, no major research (to the best of the researcher's knowledge) has been done in the topic related to our study in the UAE. This study and its valuation technique is the first of its kind for examining passengers'willingness to pay and demand for improved public transport service in the UAE.

The remaining sections of this paper are organized as follows: the analytical framework is described in the next section. Section three discusses the methodological settings while section four discusses the results obtained from descriptive and econometric analysis. The last section presents the conclusions and recommendations deduced from the study.

\section{Analytical Framework}

\subsection{Critical Literature Review}

Willingness to pay value studies have been extensively applied in a variety of areas. In the context of transport improvements, Denant and Petiot, 2003, valuate willingness to pay for improving transport information services; Walton, 2004, for improving paved road surface; Hess et al., 2005; Kumarage, 2007; and Hensher, 2006a and 2006b, for travel time savings. Specific to public transport service quality improvements, Phanikumar and Maitra, 2006, modeled willingness to pay values for rural bus attributes under different trip purposes in a developing country context; Ramanayya and Negadevara, 2007, examined transport services quality expectations and measured the willingness to pay for better services across different categories of commuters, the case of KSRTC; and Eboli and Mazzulla, 2008, examined passengers willingness to pay for improving the quality levels of a bus service in Cosenza, Italy. 
All in all, the literature shows many studies on willingness to pay estimates in the context of transport service improvements. While a large number of these studies focused on willingness to pay estimations for travel time saving, only few studies duel on willingness to pay estimations for transport service improvements in other attributes of services (such as customer handling, service frequency, reliability of buses to come on time, bus overcrowding). The literature, in general, seems to focus estimation of willingness to pay for service improvements to specific quality attributes. In this study, we consider global service improvements in a multitude of service quality attributes (Note 2). Accordingly, unlike to most other studies, we focus on valuating willingness to pay for improvement in a wider set of public bus transportation service quality attributes.

In the literature, we find that there are methods to value public goods (cf. Mitchell and Carson, 1989). These include: Hedonic pricing, Travel cost method and Contingent valuation method (CVM). Among these, CVM represent the most promising approach yet developed for determining the public's willingness to use and pay since it is capable of measuring types of benefits that the other methods cannot measure.

This study employs CVM, where we created a market scenario that resembles actual market situation for improved public transport service. The theoretical basis of CVM is welfare economics, whose theory is related to the basic theory of individual preferences and demand goods. Contingent valuation method seeks to make judgments about the desirability of having government undertake particular policies, whose interest often lies in the potential benefits as measured from consumers' current or initial level of utility.

\subsection{Valuation Methods}

According to Mitchell and Carson, 1989, goods for which ordinary market does not exist and their price determined arbitrarily, or provided freely, are considered as pubic goods. Accordingly, government owned bus transport service in the UAE is a public good or service. In literature, we find different methods to value public or non-marketable goods or services. These include those relying on revealed preferences [indirect methods such as Hedonic pricing and the household production function (e.g. Travel cost method and averting behavior] and stated preferences (direct methods) on which CVM bases (Note 3). While the former, which are based on observed economic behavior rather than consumer's stated preferences, measure only direct use value; the later measure the total value (including passive use value) of the described good or service.

On the basis of the fundamental premise of economics (that consumers have well-formed, stable preferences, and that their choices reflect these preferences); it is then possible to deduce (from choice behavior or from carefully phrased direct questions about preferences) whether transportation improvements or other public policy initiatives are socially desirable (McFadden, 1998). Contingent valuation method, being a direct valuation method, has become a common practice (cf. Carson et al., 2001) for assessing the economic value of public projects. It uses surveys with respondents from a representative sample of the population affected by a project (i.e. improvements in the service quality) with the objective of assessing its effect on their utility. Its flexibility facilitates valuation of a wide variety of non-market goods (including those not currently provided). Moreover, it represents the most promising approach yet developed for determining the public's willingness to pay for public goods (Mitchell and Carson, 1989) since it is capable of measuring types of benefits that the other methods cannot measure. More importantly, it enables researchers to assess total value (Note 4), including passive use value.

For Carson et al., 2001, the link between welfare economics and contingent valuation is quite direct. Indeed the theoretical basis of contingent valuation is welfare economics, whose theory is related to the basic theory of individual preferences and demand for goods. Policy interest usually lies on the potential benefits as measured from consumers' current or initial level of utility. In theory, such utility changes can be expressed in monetary terms by the Hicksian compensating variation (cf. Ahlheim, 1998, as sited in Weldesilassie et al., 2009):

$$
C V_{h}^{0 l}=e_{h}\left(P^{l}, z^{l}, U_{h}^{l}\right)-e_{h}\left(P^{l}, z^{l}, U_{h}^{0}\right)
$$

where $e_{h}\left[P, z, U_{h}\right]$ represents a passenger's expenditure function given a price vector $\mathrm{P}$, the level $z$ of bus service, and the passenger's utility level $U_{h}$, with 0 and 1 referring to the quality of the bus transport service before and after quality improvements respectively. The compensating variation of the utility from increased service improvements will equal to the maximum amount of money that could be extracted from the passenger after the service improvements to leave the household just as well off as without the service improvements. As a result, the compensating variation will be the passenger's willingness to pay for an improved bus service. Assuming prices and incomes held constant, equation (1) can be expressed as: 


$$
C V_{h}^{01}=e_{h}\left(P^{l}, z^{l}, U_{h}^{0}\right)-e_{h}\left(P^{l}, z^{0}, U_{h}^{0}\right)
$$

It is known as the compensating surplus for service quality change resulting from the improvements (cf. Freeman, 2003). Then, equation (2) can be expressed as the integral of the passenger's shadow price function of the public bus service.

$$
C V_{h}^{01}=\int_{z^{0}}^{z^{1}} \pi_{h}\left(P^{1}, z, U_{h}^{0}\right) d z
$$

where the shadow price function $\pi_{h}\left(P, z, U_{h}\right)=-\partial \pi_{h}\left(P, z, U_{h}\right) / \partial z$ is not observable.

Hicksian consumer surplus measures are theoretically preferred measures of consumer benefit. In order to calculate the benefits using Hicksian demand curve, it requires correctly estimating the demand function for the improvement of the public goods. However, this task is difficult, at least, due to lack of accurate market data for these goods. Thus, in practice the utility change resulting from a change from the service improvement is assessed by asking passengers in CVM interviews about their willingness to pay for the proposed service improvement. This alternative method is to use a hypothetical market model that requires the creation of a market scenario resembling the actual market situation for goods and services that does not have ordinary market (Mitchell and Carson, 1989).

Contingent valuation method uses survey question to elicit consumers' preferences for public goods or services by finding out how much they would be willing to pay in monetary value for a benefit (from the improved public bus transport service); likewise how much they would be willing to accept (WTA) in compensation for deterioration. That is, it is aimed at eliciting consumers' willingness to pay for improvement in public good in monetary amount. From the survey data obtained using CVM, not only a maximum willingness to pay data can be generated (which will be used to construct demand curves) but it can also be used to conduct valuation process of the public goods without having to estimate the actual demand curve.

A typical CVM survey entails three processes that offer many possibilities for eliciting methodologies. These include designing the survey, conducting the survey, and analysing its results using econometric techniques. Even though there is no unique standard approach to design a CV questionnaire, common to most applications of CV survey designs include (Carson et al., 2001): (a) an introductory section which sets the general context for the decision to be made; (b) a detailed description of the good or service that respondents are asked to value, and the institutional conditions and the manner under which the goods will be provided and paid for; (c) the method by which the survey elicits the respondent's willingness to pay and its preference with respect to the good; (d) debriefing questions regarding respondent's reason to answer certain questions the way they did; (e) some debriefing questions regarding respondents' characteristics including their attitude towards the good and their socioeconomic and demographic characteristics.

The researcher can elicit the respondent's willingness to pay estimates from the CV survey using different techniques. The commonly used elicitation methods (Note 5) are bidding game, payment card, discrete choice (take it or leave it offer), discrete choice with follow-up approach (Note 6), and the modified dichotomous approach. The survey can be administered using in-person interview, telephone or mail.

Contingent valuation is a useful tool for benefit-cost analysis and other purposes where knowledge of the willingness to pay distribution and its relationship to other variables (such as age, income, and location) of interest provided it is properly executed. Although it is the most frequently used valuation technique, debate persists over its reliability. The most alleged weaknesses with the use of contingent valuation is the potential for survey respondents to give biased answers which include strategic bias (Note 7), interviewer (or compliance) bias (Note 8), and information bias (Note 9). Other possible biases include starting point bias, which can be associated with the choice of a higher (or lower) starting willingness to pay point leading to a low (high) mean willingness to pay value, and hypothetical bias (Note 10). In this study, attempt was made to ensure the applicability of the CVM in the context of public bus service quality improvements.

\section{Methodological Settings}

\subsection{Data Type and Source}

Both primary and secondary (Note 11) data sources are used for this study. The type of data used in the study is mainly primary and cross-sectional for the year 2012 obtained from the contingent valuation survey of a random-purposive (Note 12) sample of 852 residents of UAE, mainly in the Emirate of Dubai. This primary data is collected through in-person interview and mail by means of a CV questionnaire. Soliciting the respondents' willingness to use and pay for improved public bus service being the major objective of the CV survey, other 
socioeconomic and demographic questions as well as their preferences to the forms of payment for the improved service are also included in the survey.

The elicitation method in this study follows the discrete choice with a follow-up approach, in which the respondent is asked a yes or no answer-question regarding his/her willingness to use as well as willingness to pay (in United Arab Emirates Dirham, AED) for an improved public bus service. The later was followed by other question/s using a higher price if the respondent says yes until [s] he says 'no'. Likewise, if the respondent says no, a lower price is used in the follow-up question until [s] he says 'yes'.

\subsection{Survey Design and Procedure}

The survey instruments were designed to gather respondents' basic socioeconomic, demographic and transportation characteristics. Furthermore, a discrete choice with follow-up approach is used to elicit passenger's willingness to use and pay for an improved public bus service. In this approach, a hypothetical description of the circumstances under which the improved bus service will be made available were provided. Respondents were briefed about RTA's plan to improve the quality of public transport in Dubai to reach the highest international standards in its services. The specific amenities of the plan that are briefed to the respondents are described in Box-1. This is followed by questions that elicit the respondent's willingness to use and pay for the improved service. The passenger is asked whether or not [s] he is willing to pay AED 3.00 per trip (Note 13). Depending on the respondent's answer is 'yes' or 'no', the question is repeated by increasing or decreasing the bid by AED 0.50 until the respondent states his/her maximum willingness to pay value. The last section of the survey instrument includes respondents' general suggestions regarding their preferences to transport policy options that may help policy makers formulate informed decisions in their effort to improve the public transport service, thereby contributing towards mitigating traffic-jam and pollution.

\begin{tabular}{|l|}
\hline Box 1. Amenities of the hypothetical improved public bus service \\
\hline - \\
- Renewal/building of all stations (with air conditioner, thin film transistor \\
(TFT) screens, bus timings announcements, etc.). \\
- Rutomated Vehicle Management (AVM) system providing real information. \\
information (monitoring each bus) by means of electronic displays, making it \\
possible to inform the passengers about delays or the status of \\
interconnections they might wish to make and so on. \\
- Maintaining schedule time (posted). \\
- Minimizing (10 to 15 minutes) waiting time at stations. \\
- Minimizing traveling time (e.g. by specifying routes priorly for bus). \\
- Providing special fuel for buses which cause minimal air pollution.
\end{tabular}

In designing and conducting the survey, attempt was made to minimize biases that may arise in using CVM such as interviewer bias (Note 14), strategic, hypothetical and compliance biases, and scenario specification. Before the main survey was conducted, training was given to enumerators who are all university and college students. We conducted a pretest survey that helped the enumerators to administer CV survey as well as to check the wording and structuring of the questionnaire.

\subsection{Empirical Model}

The framework for this analysis is provided by the random utility model. In the random utility model, the decision-maker (the passenger) is assumed to choose the outcome (whether to use the improved public bus service or not) that maximizes his/her utility. Since this utility is not observable, rather some attributes of the alternatives as faced by the decision-maker are observable, the utility is decomposed into deterministic (or a systematic) component $V_{i j}$ and random component $\epsilon_{i j}$ of utility:

$$
U_{i j}=V_{i j}+\epsilon_{i j}, \quad \text { for all } i=1,2, \ldots, N \text { and } j=1,2, \ldots, J
$$

where $U_{i j}$ is the level of utility the individual decision-maker $i$ obtains from choosing alternative $j . \epsilon_{i j}$ (which represents the unknown components (Note 15) of the resident's utility function) is assumed to be independently and identically distributed with type I extreme value (Gumbel) distribution (Greene, 2011). 
Decision maker $i$ chooses alternative $j$ if

$$
\begin{gathered}
U_{i j}>U_{i k}, \text { for all } k \neq j \\
V_{i j}\left(z_{i}, s_{i}, \beta_{i}\right)+\epsilon_{i \mathrm{j}}>V_{i k}+\epsilon_{i k}
\end{gathered}
$$

where the deterministic part is a function of the observed attributes $(z)$ of the choice as faced by the individual $i$, his/her observed socioeconomic attributes $(s)$ and a vector of parameters $(\beta)$.

Since $\epsilon_{i j}$ is not observed, the decision-maker's choice cannot be predicted exactly. Instead, the probability of any particular outcome is derived. The probability that decision-maker $i$ chooses outcome individual $j\left(i . e . P_{i j}\right)$ is equal to the probability that the utility of alternative outcome individual $j$ is greater than the utilities of all other alternatives in the choice set (cf. Greene, 2011):

$$
\begin{aligned}
P_{i j} & =P_{r}\left(U_{i j}>U_{i k}\right), \text { for all } k \neq j \\
& =P_{r}\left(V_{i j}+\epsilon_{i j}>V_{i k}+\epsilon_{i k}\right)
\end{aligned}
$$

The above equation shows that the choice probability, $P_{i j}$, depends only on the difference in utility; not on its absolute level. This implies that, in general, the only parameters that can be estimated (or identified) are those that capture differences across alternatives.

The specific form of the above discrete choice model is determined by the assumed distribution of the random component, $\epsilon_{i j}$ and the specification of the deterministic component, $V_{i j}$. While the latter is often treated as a linear function of explanatory variables and unknown vector of underlying parameters, $Q$; the expectation of the former (i.e. $\left.E\left(\epsilon_{i j}\right)\right)$ is assumed be zero in random utility models, implying that $E\left(U_{i j}\right)=V_{i j}$ (cf. Ivan and Katarina, 2003, sited in Genanew and Schneider, 2009).

Given the above assumptions, the unknown parameter $(Q)$ of the discrete choice model can be estimated to examine the way how observed factors influence the decision maker's choice. The log-likelihood estimator can be used to estimate the parameters, for which the log-likelihood function to be maximized over parameters $Q$ can be given by:

$$
\ln L(Q)=\sum_{i=1}^{N} \sum_{j=1}^{J} y_{i j} \ln P_{i j}
$$

where $y_{i j}$ equals 1 if alternative $j$ is chosen and 0 for all other non-chosen alternatives.

\subsubsection{Modeling Willingness to Use and Willingness to Pay for the Improved Public Bus Service}

A discrete econometric model is used to capture passengers' preference between the existing and proposed improved public bus services. The model works with the random utility functions explained above. The utility derived from the improved public bus service may be expressed as a function of several attributes. Equation (4) can alternatively be expressed as:

$$
U_{i j}=X_{i j}^{\prime} \beta+\epsilon_{i j}, \text { for all } i=1,2, \ldots, N \text { and } j=1,2, \ldots, J
$$

where $U_{i j}$ is the utility arising from choosing alternative $j$ by the individual decision-maker $i, X_{i j}^{\prime} \beta$ is the deterministic component of the utility function, $X_{i j}$ is a vector of observable factors that influence utility, and $\beta$ is a parametric vector. Thus, decision maker $i$ chooses alternative $j$ if and only if

$$
U_{i j}>U_{i k} \text { or } \Delta U=U_{i j}-U_{i k}>0, \text { for all } j \neq k
$$

The random utility model depends on the deterministic and random components. Hence, the change in utility associated with an improvement in bus service quality is equal to the change in the deterministic and random components. Therefore, willingness to pay (WTP) depends on the change in the deterministic and random components of utility (cf. Cranfield and Magnusson, 2003). Alternatively, willingness to pay can be written as:

$$
W T P=X^{\prime} \beta+\epsilon \text {, where } X=X_{i j}-X_{i k} \text { and } \epsilon=\epsilon_{i j}-\epsilon_{i k}
$$

Willingness to pay is determined by the degree to which utility changes through the resident's choices between the existing and the improved public bus services. The larger the increase in utility, the larger the maximum amount a resident would be willing to pay. Moreover, WTP is expected to vary across residents, and hence resident's characteristics can be included among the factors that may determine willingness to pay. It will then be 
possible to use the relationship between WTP and determinants of WTP to predict the probability of a resident's WTP being in between a specified lower and upper bounds. The difference in these probabilities shows the likelihood that resident's WTP being between the defined amounts. That is,

$$
P(\underline{W T P}<W T P \leq \overline{W T P})=P\left(X^{\prime} \beta+\epsilon \leq \bar{\gamma}\right)-P\left(X^{\prime} \beta+\epsilon \leq \underline{\gamma}\right)
$$

where $P(\cdot)$ is the probability of operator, $\underline{W T P}$ and $\overline{W T P}$ are lower and upper limits of $W T P$, and $\bar{\gamma}$ and $\underline{\gamma}$ are threshold changes in utility consistent with the lower and upper ranges of WTP.

In this study, WTP is a multiple response variable with intrinsic ordered values. Consequently, ordered response model is suitable in this analysis. In this study, the WTP model can be written using the latent (unobserved) variable as in equation 12 :

$$
\widetilde{W T P}=X^{\prime} \beta+\epsilon
$$

where $\widetilde{W T P}$ is the resident's latent willingness to pay, and $X$ and $\epsilon$ are as defined above.

If the resident's latent WTP falls within a specific range, her WTP is assigned a numerical value that reflects the category in which her latent WTP lies. Particularly, if

$$
\gamma_{j-1}=\widetilde{W T P} \leq \gamma_{j}, \text { then } W T P=j-1, \text { for all } j=1,2, \ldots, J
$$

where $j$ is the WTP category selected by the respondent, and $\gamma_{\mathrm{k}}$ are category threshold parameters (Note 16) that are unobservable but can be statistically estimated. Now, the probability of a WTP being in one of the $J$ finite categories can be written as:

$$
P(W T P=j-1)=\Phi\left(\gamma_{j}-X^{\prime} \beta\right)-\Phi\left(\gamma_{j-1}-X^{\prime} \beta\right) \forall j \in J
$$

where $\Phi(\cdot)$ is a cumulative density function (CDF), which measures the probability of WTP being less than the respective threshold level. Empirically, the CDF can be chosen to be either the standard normal or logistic density functions. If $\Phi(\cdot)$ is the standard normal density function, the resulting probability model is ordered probit; if $\Phi(\cdot)$ is the logistic density, the resulting probability model is ordered logit. The ordered logit model is used in this study (Note 17).

And the willingness to use (WTU) the improved public bus service, in this study, takes two alternative responses. And it can be written, without loss of generality, as $U=X^{\prime} \beta+\epsilon$, where $X$ and $\epsilon$ are as defined in (Equation 10). Consequently, we need a model that describes the probability of a particular passenger's decision to prefer the improved public bus service or not. A probit model (Equation 15) is used to estimate the passenger's probability of deciding to prefer the improved public bus service:

$$
P(Y=W T U)=X^{\prime} \beta+\epsilon
$$

where $Y$, the dependent variable, takes 0 if the passenger does not prefer the improved service; and 1 otherwise. $X$ is a vector of attributes characterizing the passenger and the public transport services, $\beta$ is vector of parameters to be estimated, and $\epsilon$ is an error term used to capture unobservable factors and its distribution is assumed to be independently and identically distributed with mean zero and variance one.

\section{Results and Analysis}

This section presents the findings of the contingent valuation survey using a descriptive and econometric analysis.

\subsection{Results of Descriptive Analysis}

\subsubsection{Socioeconomic and Demographic Characteristics}

A total of 852 UAE residents were surveyed for this study. Out of this, 50 percent are male respondents and about 63 percent are single while married, divorced and widowed represent 33, 3, and 1 percent respectively. On average, the age of the respondent is 27.4 years ranging from 18 to 67 years of age. While the education level of the majority (about 73 percent) is college/university, high school level respondents represent 20 percent, and those with education level of primary school and no education are the minorities respectively representing 3 percent and 2 percent of the total respondents, and 2 percent represent other type of informal education. UAE-locals represent 45 percent of the survey respondents and 55 percent are non-locals.

The data on employment status of the respondents revealed that 63 percent are employed; out of which 40 
percent work on private businesses, 33 percent are government employees, 11 percent are self-employed (own business), and 16 percent are engaged in other types of employment. Out of all the employed respondents, 87 percent are working on permanent/full-time bases, 10 percent are working on part-time basis, and 2 percent work in temporary/seasonal jobs. Out of the 37 percent unemployed respondents; 59 percent are pensioners and retirees, 30 percent are students, and others represent 11 percent.

The study shows that a respondent earns, on average, a monthly income of AED 11,373 (ranging from AED 400 to AED 60,000); while the average family monthly income and expenditure are AED 38,832 and AED 13,557 respectively. On average, a household monthly expends AED 858 on transportation (3 percent of which is on public bus and about 85 percent on private cars), AED 6,765 on education, AED 2,044 on food and beverage, AED 1,179 on utilities, AED 1,402 on telephone (both internet and phones), AED 602 on health, and AED 705 on other items.

With regard to living and working in the UAE, a resident has been living in the UAE for about 19 years (ranging from 6 months to 50 years). The majorities of the respondents ( 78 percent) are residents of Dubai; followed by Sharjah (17 percent), Ajamn (2.3 percent), Abu Dhabi (1 percent) and other emirates (1.7 percent). While the majority (83 percent) would like to continue living in Dubai, 13 percent prefer to move to other cities within the UAE, and only about 4 percent want to leave UAE. Of those who want to leave Dubai, 50 percent reasons living expense as their major decision factor to move. With regard to respondents prior reason to choose Dubai as a place of living and work, its security and job opportunity were rated the utmost reasons and quality of public transport service was rated the least.

\subsubsection{Transportation Characteristics}

In order to understand the characteristics of transportation in Dubai, some selected indicators are taken into consideration. These include ownership of car, means of transport often used, travel time from residence to work/study place, cost of transportation, perception of quality of public bus transport service and public bus transportation area coverage. Sample responses show that about 69 percent of residents own private car. In terms of the type of transport mode, the majority (68 percent) of the respondents often use own private car and only 9 percent use public bus while a few (2.6 percent) use metro. At the family level, own private car is the utmost mode of transportation used (about 78.6 percent). The survey indicates, as expected, that non-own private car transport modes are less preferred by families than individuals. Public bus and metro are the least used.

Among the public transport users, a resident, on average, uses public bus transport mode once (trip) per day and spends about an hour and quarter (in round trips) traveling from residence to work/study places using public bus while [s] he spends about 55 minutes using taxi or private car. On the other hand, it takes only about 42 minutes (in round trips) traveling from residence to work/study places using metro.

Transportation cost in Dubai is rated as expensive or very expensive by about 41 percent of the sample respondents, and only 9 percent rated as either cheap or very cheap while the cost is rated fair for the majority (50 percent). On average, a household monthly expends AED 858 on transportation and this cost is self (own or family) sponsored for about 88 percent of the respondents while it is company sponsored for only 10 percent of the respondents.

Public transport service quality in Dubai, in general, is rated as either very good or excellent by only about a quarter of the respondents, and is rated as poor by about 6 percent of the respondents. In terms of specific indicators of quality service attributes, metro service is rated superior than public bus by all indicators of service delivery (see table 1). Except for safety, which on the average is rated good, public bus service delivery is rated mediocre by all indicators. Comfort of waiting stations, waiting time, travel time and noise/crowdedness/smell are rated the least.

At the current state of public bus transport service in Dubai, many respondents are reluctant to use public bus. Even if bus stations will be located near to their residence, 61.2 percent of the respondents are not willing to use the public bus. About half of the respondents feel that public transport in Dubai is not safe to be used for children by their own. 
Table 1. Respondents rating of public transport service quality attributes in Dubai

\begin{tabular}{|c|c|c|c|c|c|c|c|c|c|c|c|c|}
\hline \multirow{4}{*}{$\begin{array}{c}\text { Public transport service } \\
\text { quality attributes }\end{array}$} & \multicolumn{6}{|c|}{ Public bus } & \multicolumn{6}{|c|}{ Metro } \\
\hline & \multicolumn{5}{|c|}{ Percentages } & \multirow{3}{*}{ Mean } & \multicolumn{5}{|c|}{ Percentages } & \multirow{3}{*}{ Mean } \\
\hline & $\mathrm{VG}^{*}$ & $\mathrm{G}$ & $\mathrm{N}$ & $P$ & VP & & VG & $\mathrm{G}$ & $\mathrm{N}$ & $P$ & VP & \\
\hline & (5) & (4) & (3) & (2) & (1) & & (5) & (4) & (3) & (2) & (1) & \\
\hline Safety & 24 & 30 & 30 & 9 & 7 & 3.54 & 7 & 36 & 13 & 3 & 1 & 4.24 \\
\hline Cleanness & 19 & 26 & 31 & 17 & 7 & 3.33 & 50 & 34 & 13 & 3 & 1 & 4.28 \\
\hline Comfort of seats & 15 & 29 & 33 & 16 & 7 & 3.31 & 41 & 34 & 19 & 4 & 2 & 4.09 \\
\hline Waiting stations comfort & 13 & 24 & 32 & 20 & 11 & 3.09 & 37 & 37 & 20 & 4 & 2 & 4.05 \\
\hline Waiting time & 8 & 22 & 34 & 24 & 12 & 2.91 & 32 & 38 & 22 & 6 & 2 & 3.93 \\
\hline Traveling time & 10 & 24 & 35 & 19 & 12 & 3.00 & 35 & 34 & 23 & 7 & 2 & 3.94 \\
\hline Ticket fee & 17 & 30 & 35 & 12 & 6 & 3.43 & 31 & 31 & 27 & 9 & 2 & 3.81 \\
\hline $\begin{array}{l}\text { Proximity of stations to/from } \\
\text { residence-work place }\end{array}$ & 12 & 26 & 38 & 16 & 8 & 3.18 & 26 & 29 & 26 & 12 & 7 & 3.57 \\
\hline Driver's customer handling & 12 & 29 & 35 & 15 & 9 & 3.21 & 37 & 31 & 25 & 5 & 2 & 3.95 \\
\hline Noise/crowdedness/smell & 10 & 17 & 30 & 22 & 21 & 2.73 & 31 & 32 & 25 & 9 & 3 & 3.79 \\
\hline Air conditioning & 18 & 28 & 30 & 14 & 10 & 3.32 & 41 & 36 & 16 & 6 & 1 & 4.12 \\
\hline
\end{tabular}

*VG, G, N, P and VP respectively represent very good, good, neutral, poor, and very poor ratings.

\subsubsection{Willingness to Use and Pay for Improved Public Bus Service}

Respondents were asked about their willingness to use and pay for improved public bus transport service. Prior to these questions, respondents were briefed about RTA's plan to improve the quality of the public transport in Dubai to reach the highest international standards in its services. Box-1 (see section 3.2) specifies the amenities of the plan that are briefed to the respondents.

Given these amenities as a hypothetical scenario of future public bus service improvements, the respondents were asked different questions that enable us to capture their opinion about their willingness to use and pay for the improved public bus service as well as their preferences to the types of payment for the service. Accordingly, the result of the contingent valuation survey indicates that more than 75 percent of the respondents are willing to use the improved public bus service. Of these that are willing to use the improved service, 60 percent are willing to use the improved service only sometimes, while 24 percent and 16 percent are willing to use it often and always respectively.

In terms of fees, the majority (more than 60 percent) are willing to pay up to AED 3 per trip if RTA provides the improved bus service. On average, a respondent is willing to pay a maximum of AED 3.20 per trip for the improved public bus service. The results of the survey also indicate that more than 70 percent of the respondents are willing to pay more than AED 2.00 per trip. Respondents are willing and able to pay up to 10 percent of their monthly income to get the improved public bus transport service. However, they need to see some facilities installed in a public bus. While 55.2 percent would like to watch television while traveling using a public bus, 28.1 percent favor radio and 32 percent wishes to see coffee machine installed in the public bus. Different modes of payments were stated by respondents. Accordingly, 48.7 percent prefer to pay per each trip, 12.5 prefer weekly payment card and 38.8 prefer monthly payment card.

As a policy simulation exercise, respondents were asked about their preferences, attitudes and options that may help policy makers formulate informed decisions in their effort to improve the public transport services, thereby contributing towards mitigating traffic-jam and pollution. Accordingly, policy instruments vis-à-vis direct pricing measures are less favored. For instance, about 57 percent of the respondents disagree increasing price of car (e.g. through higher fees or taxes) to encourage people to use public transport' as a policy option. Likewise only 14 percent of the respondents agree 'increasing price of fuel to encourage people to use public transport' as a policy option. On the other hand, soft policy measures such as 'having incentive mechanism to discourage use of parking areas for staffs in companies and provide employees with bus services', 'encouraging people (e.g. 
special membership or offer card, by giving extra credit for spending more per month on public transport'), and 'creating awareness (e.g. using advertisement) on the need for public transport in reducing traffic-jam and pollution' are the preferred options by the majority of the respondents. Each of these measures receives the agreement of 52 percent, 51 percent and 58 percent of the respondents respectively.

\subsection{Determinants of Willingness to Use the Improved Public Bus Service}

A descriptions of the variables included in the empirical model are provided in table 2. For the willingness to use, the empirical model was estimated using PROBIT command in STATA, a maximum likelihood estimator for probit model (Long and Freese, 2006). Parameter estimates and summary statistics of the probit model are presented in table 3.

Table 2. Variable description

\section{Variables}

Description

Maximum willingness to pay for improved bus service per In United Arab Emirates Dirham (AED) trip (WTP per trip)

Gender of the respondent

Age of the respondent

Marital status of the respondent

Education level of the respondent

Nationality of the respondent

Employment type of the respondent (own business or not)

Total family monthly income

Duration of stay in the UAE

Respondent live in Dubai

Respondent owns car

Respondent often use the existing public bus

Respondent often use Metro

Number of bus trips the respondent uses per day

Respondent's rating of bus transportation cost in Dubai

Average home to/from work travel time by bus per trip

Respondent's rating of bus transport service quality in Dubai

Respondent's willingness to use bus if station is near home/work place

Respondent believe that bus is safe for children

Respondent believe that people need incentives to spend more on public bus

Respondent is willing to use carpooling if provided by RTA

Monthly fee the respondent is willing to pay for carpooling
0 if male and 1 if female

Number of years

1 if married and 0 if otherwise

1 if no formal education, 2 if primary school, 3 if high school, and 4 if college/university

0 if non-local and 1 if UAE local

1 if own self-business and 0 if otherwise

In United Arab Emirates Dirham (AED)

Number of years

1 if living in Dubai and 0 if otherwise

1 if own private car and 0 if not

1 if often use public bus and 0 if not

1 if often use public Metro and 0 if not

Number of trips

1 if very expensive, 2 if expensive, 3 if fair, 4 if cheap, and 5 if very cheap

In minutes per trip

1 if poor, 2 if satisfactory, 3 if good; 4 if very good, and 5 if excellent

1 if willing to use and 0 if not willing to use

1 if yes and 0 if otherwise

1 if agree, 2 if neutral and 3 if disagree

1 if agree, 2 if neutral and 3 if disagree

In United Arab Emirates Dirham (AED)

The probit model is non-linear and hence the estimated coefficients are not marginal effects and thus will be discussed separately. The result shows that the null hypothesis that the estimated coefficients are jointly equal to zero is rejected at the 1 percent level. Of the 22 variables estimated coefficients, 10 are significant at least at 10 percent level. Coefficients for the per trip willingness to pay, respondents willingness to use bus if station is near home/work place, respondents belief that people need to be encouraged (such as through monetary incentives) to 
spend more on public buses, and respondents willingness to use carpooling if provided by RTA are significant at the 1 percent level. Employment type, family income, car ownership, bus transport service rating, and the dummy variable indicating whether respondents believe that bus is safe for children are significant at the 5 percent level. The coefficient for the dummy variable indicating respondent's frequent use of the existing bus service is significant at 10 percent level.

Table 3. Maximum likelihood estimates, predicted probabilities and marginal effects of the probit model

\begin{tabular}{|c|c|c|c|}
\hline Variables & $\begin{array}{c}\text { Parameter } \\
\text { estimate (z-value) }\end{array}$ & $\begin{array}{c}\text { Marginal } \\
\text { effects }\end{array}$ & $\begin{array}{l}\text { Mean } \\
\text { values }\end{array}$ \\
\hline Maximum willingness to pay for improved bus service per trip & $0.195(5.90)^{* * *}$ & 0.059 & 3.197 \\
\hline Gender of the respondent & $-0.096(-0.90)$ & -0.029 & 0.495 \\
\hline Age of the respondent & $-0.004(-0.52)$ & -0.001 & 27.386 \\
\hline Marital status of the respondent & $0.169(1.30)$ & 0.051 & 0.365 \\
\hline Education level of the respondent & $-0.064(-0.78)$ & -0.019 & 3.637 \\
\hline Nationality of the respondent & $-0.080(-0.63)$ & -0.024 & 0.446 \\
\hline Employment type of the respondent (own business or not) & $-0.297(-2.39)^{* *}$ & -0.095 & 0.249 \\
\hline Total family monthly income & $-0.000(-2.25)^{* *}$ & -0.000 & 38831.6 \\
\hline Duration of stay in the UAE & $-0.004(-0.56)$ & -0.001 & 18.902 \\
\hline Respondent live in Dubai & $0.027(0.20)$ & 0.008 & 0.784 \\
\hline Respondent owns car & $-0.287(-1.96)^{* *}$ & -0.084 & 0.691 \\
\hline Respondent often use the existing public bus & $0.555(1.79)^{*}$ & 0.139 & 0.090 \\
\hline Respondent often use Metro & $0.352(0.86)$ & 0.093 & 0.026 \\
\hline Number of bus trips the respondent uses per day & $0.005(0.10)$ & 0.002 & 0.761 \\
\hline Respondent's rating of bus transportation cost in Dubai & $-0.052(-0.81)$ & -0.016 & 3.394 \\
\hline Average home to/from work travel time by bus per trip & $0.002(0.31)$ & 0.001 & 37.998 \\
\hline Respondent's rating of bus transport service quality in Dubai & $0.150(2.39)^{* *}$ & 0.046 & 2.989 \\
\hline $\begin{array}{l}\text { Respondent's willingness to use bus if station is near } \\
\text { home/work place }\end{array}$ & $0.883(6.93)^{* * *}$ & 0.246 & 0.389 \\
\hline Respondent believe that bus is safe for children & $0.209(1.96)^{* *}$ & 0.064 & 0.5 \\
\hline $\begin{array}{l}\text { Respondent believe that people need incentives to spend more } \\
\text { on public bus }\end{array}$ & $-0.294(-3.90)^{* * *}$ & -0.089 & 1.617 \\
\hline Respondent is willing to use carpooling if provided by RTA & $-0.274(-4.07)^{* * *}$ & -0.083 & 2.116 \\
\hline Monthly fee the respondent is willing to pay for carpooling & $0.001(1.26)$ & 0.000 & 190.018 \\
\hline Constant & $0.998(1.56)$ & & \\
\hline Predicted probabilities & & 0.769 & \\
\hline
\end{tabular}

Log likelihood $=-394.66$

Pseudo $\mathrm{R}^{2}=0.2410$

Likelihood ratio test of zero slope coefficients $(23)=250.58^{* * *}$

* Significant at the 10 percent.

** Significant at the 5 percent.

*** Significant at the 1 percent.

The estimated predicted probability for the willingness to use, evaluated at the sample means of the data, is presented at the last row of table 3 . This probability indicates a strong likelihood that the average UAE resident is willing to use the improved public bus service. In order for the UAE government to achieve its vision (cf. Dubai Strategic Plan, DSP 2015) of increasing the share of public transportation and decreasing transport by private vehicles, effort will have to continue to improve the public bus service quality since a major fraction of residents (about 77 percent) are willing to use the improved service. There is knowledge that residents, in general, are willing to use public bus provided its service quality is improved. This should provide assurance to RTA who 
may be concerned about the potential demand for improved public bus service. However, this predicted probability is not very informative when taken alone. Assessing the impact of a change in an explanatory variable on the predicted probability (i.e. marginal effects) will be more revealing.

The third column of table 3 shows the marginal effect of each explanatory variable, assuming all remaining variables take their respective average values. These effects show the change in the predicted probability for the willingness to use for an average respondent, according to the explanatory variable being considered. The result shows that a 1 AED increase in the respondent's per trip willingness to pay for the improved public bus service increases the probability of using the improved service by 6 percentage points. Having own business decreases the probability of using the improved bus service by 10 percentage points. Though its magnitude of effect is not substantial, respondent's family income negatively affects willingness to use the improved public bus service.

The 'car ownership' dummy variable has a negative marginal effect. Being a car owner decreases the probability of using the improved public bus service by 8.4 percentage points. This suggests that car owners are, in general, less willing to use the improved public bus service than those without private car. This result emphasizes the need for market incentives to pull-down personal car ownership demand into public transport services (such as bus and/or metro).

Being a respondent who often use the existing public bus service increases the probability of using the improved public bus service by 14 percentage points. If the improved service is provided, residents using the existing public bus service will remain to be the frequent users of the bus service. Respondents' rating of the existing public bus service is positively related with their willingness to use the improved public bus service. Respondents who believe that the existing public bus service is not poor want to see more improvement in the proposed public bus service. The result also shows that respondents' willingness to use the improved bus service is strongly related to the availability of bus station near to their home or work place. Having bus station near home or work place increases the probability of using the improved public bus service by 25 percentage points. Respondents who believe that bus is safe for children are more willing to use the improved public bus service than those who believe otherwise. Having a belief that public bus is safe for children increases the probability of using the improved public bus service by 6.4 percentage points.

Respondents who believe on the need for RTA incentives to use public bus are, in general, more willing to use the improved public bus service. Being a believer of the need for such an incentive increases the probability of using the improved public bus service by about 9 percentage points. And respondents who are willing to use carpooling if provided by RTA show positive willingness to use the improved public bus service. Willingness to use carpooling (if provided by RTA) increases the probability of using the improved public bus service by 8.3 percentage points. This emphasizes that RTA need to diversify its service provision to include other alternatives (such carpooling in mini-buses). Such alternatives will amplify its endeavor to increase the share of public transportation.

\subsection{Determinants of Willingness to Pay for Improved Public Bus Service}

For the willingness to pay, the empirical model was estimated using OLOGIT in STATA, a maximum likelihood estimator for ordered logistic model (Long and Freese, 2006). Table 4 shows the range of possible willingness to pay categories and distribution of responses (Note 18).

Table 4. Distribution of willingness to pay responses

\begin{tabular}{lcc}
\hline \multicolumn{1}{c}{ WTP category } & Frequency & Proportion (\%) \\
\hline Willing to pay up to AED 2 per trip & 246 & 28.87 \\
Willing to pay above AED 2 and up to AED 3 per trip & 299 & 35.09 \\
Willing to pay above AED 3 and up to AED 4 per trip & 122 & 14.32 \\
Willing to pay above AED 4 per trip & 185 & 21.71 \\
\hline
\end{tabular}

Parameter estimates and marginal effects of the ordered logistic model are presented in table 5. The ordered logistic model is non-linear and hence the estimated coefficients are not marginal effects and thus will be discussed separately. The result shows that the null hypothesis that the estimated coefficients are jointly equal to zero is rejected at the 1 percent level. Out of the 22 estimated coefficients, 10 are significant at least at 10 percent level. The coefficients for the nationality dummy variable, the dummy variable indicating whether or not the respondent often use the existing bus service, number of bus trips the respondent uses per day, and respondent's 
rating of bus transport cost in Dubai are significant at the 1 percent level. The dummy variable indicating respondents' willingness to use bus if station is near home/work place and 'monthly fee the respondent is willing to pay for carpooling' variable are significant at the 5 percent level. The coefficient for age, age-squared, car ownership dummy and the dummy variable indicating whether the respondent believes that bus is safe for children are significant at the 10 percent level. The estimated threshold levels defining the different willingness to pay categories are significant at the 1 percent level.

The estimated predicted probabilities for the four willingness-to-pay categories, evaluated at the sample means of the data, are presented at the last row of table 5. These probabilities indicate a strong likelihood that the average UAE resident is willing to pay the improved public bus service. Given that RTA's motive is not purely monetary profit, understanding the maximum willingness to pay amount (and hence the consumers' surplus) for using an improved public bus service is imperative. The result (particularly the predicted probabilities for the third and fourth categories) suggests that there is the knowledge that residents, in general, are willing to pay higher premiums for using public bus provided its service quality is improved. This should provide assurance to RTA who may be concerned about the potential demand for improved public bus service. In order for the UAE Government to increase the share of public transportation and decrease transport by private vehicles, effort will have to continue to improve the public bus service quality. In particular, marketing of such improved service will have to focus on the fraction of residents who are in the first and second willingness to pay categories.

Predicted probabilities are not very informative when taken alone. Assessing the impact of a change in an explanatory variable on the predicted probabilities (marginal effects) will be more informative. The last four columns of table 5 shows the marginal effects for the explanatory variables included in the ordered logistic model, assuming all remaining variables take their respective average values. The result confirms that the dependence of willingness to pay on age is U-shaped, and respondent's willingness to pay for the improved public bus service alters at the age of about 38 years ('middle age'). Until this age, the marginal effect of age is positive for the "willing to pay up to AED 2 per trip" and "willing to pay above AED 2 and up to AED 3 per trip" categories, but negative for the other willingness to pay categories. As age increases, the probability of being willing to pay up to AED 3 per trip increases, while the probability of being willing to pay more than AED 3 per trip falls. Nevertheless, once the resident crosses the middle age, the effect of age on willingness to pay is contrary to that of the younger age group. After the middle age, the marginal effect of age is negative for the "willing to pay up to AED 2 per trip" and "willing to pay above AED 2 and up to AED 3 per trip" categories, but positive for the other WTP categories. As age increases, the probability of being unwilling to pay "up to AED 3 per trip" increases, while the probability of being willing to pay more than AED 3 per trip increases. The result, in general suggests, that the young are less willing to pay higher premiums for the improved public bus service than the 'matured' group.

The marginal effects for the nationality dummy variables have negative effects for the first two categories, but positive effects on all other willingness to pay categories. These results indicate that local respondents (relative to the non-local respondents) are less likely to be willing to pay less than AED 3 per trip but more likely to pay a premium of more than AED 3 per trip for using the public bus provided its service quality is improved. The "car ownership" dummy variables have negative marginal effects for the first two WTP categories, but positive effect on all other willingness-to-pay categories. This result together with the probit estimation result suggests that a car owner is, in general, willing to pay a higher premium for using the improved public bus service provided the car owner has made a decision to use the improved public bus service.

Except for the first willingness to pay category, the marginal effects for the "respondents often use the existing public bus service" dummy variables are negative. This suggests that respondents who often use the existing public bus service are less willing to pay a higher premium for using the improved public bus service. Though these respondents show a higher willingness to use the improved public bus service (see the probit estimation result), they want RTA to maintain the current lower tariff even after the improvement of the bus service quality. On the other hand, as the number of trips of using the existing public bus per day increases, the probability of being willing to pay a higher premium for the improved public bus service increases. This is implied from the negative marginal effects (see table 5) for the first two willingness to pay categories, and the positive marginal effects for the last two willingness to pay categories.

The "bus transportation cost rating" variable has positive marginal effects for the first two willingness to pay categories, but negative marginal effects for the last two willingness to pay categories. Respondents who are contented (i.e. rated as either cheap or very cheap) with their bus transportation cost have a lower probability of being willing to pay more than AED 3 per trip for using the improved public bus service. These contented respondents want their transportation cost unaffected (i.e. they are willing to pay only a premium similar to the 
current public bus service) even after the provision of the improved bus service.

Table 5. Maximum likelihood estimates, predicted probabilities and marginal effects of the ordered logit model

\begin{tabular}{|c|c|c|c|c|c|}
\hline \multirow[t]{2}{*}{ Variable } & \multicolumn{2}{|l|}{ Parameter } & \multicolumn{3}{|c|}{ Marginal effects } \\
\hline & Estimate (z-values) & $\mathrm{WTP}=0$ & $\mathrm{WTP}=1$ & $\mathrm{WTP}=2$ & $\mathrm{WTP}=3$ \\
\hline Gender of the respondent & $0.181(1.38)$ & -0.036 & -0.005 & 0.012 & 0.0292 \\
\hline Age of the respondent & $-0.081(-1.76)^{*}$ & 0.016 & 0.002 & -0.005 & -0.0132 \\
\hline Respondents age squared & $0.0012(1.90)^{*}$ & -0.000 & -0.000 & 0.0002 & 0.0002 \\
\hline Marital status of the respondents & $-0.244(-1.51)$ & 0.049 & 0.0066 & -0.016 & -0.039 \\
\hline Education level of the respondent & $0.047(0.50)$ & -0.009 & -0.001 & 0.003 & 0.008 \\
\hline Nationality of the respondent & $0.553(3.47)^{* * *}$ & -0.108 & -0.019 & 0.036 & 0.091 \\
\hline $\begin{array}{l}\text { Employment type of the respondent (own business or } \\
\text { not) }\end{array}$ & $-0.132(-0.86)$ & 0.027 & 0.003 & -0.009 & -0.021 \\
\hline Total family monthly income & $-0.000(-0.55)$ & 0.000 & 0.000 & -0.000 & -0.000 \\
\hline Duration of stay in the UAE & $-0.005(-0.66)$ & 0.001 & 0.000 & -0.000 & -0.001 \\
\hline Respondent live in Dubai & $-0.217(-1.39)$ & 0.042 & 0.009 & -0.014 & -0.036 \\
\hline Respondent owns car & $0.323(1.84)^{*}$ & -0.066 & -0.006 & 0.022 & 0.050 \\
\hline Respondent often use public bus & $-0.867(-3.37)^{* * *}$ & 0.195 & -0.023 & -0.060 & -0.112 \\
\hline Respondent often use Metro & $-0.084(-0.21)$ & 0.017 & 0.002 & -0.006 & -0.013 \\
\hline Number of bus trips the respondent uses per day & $0.234(4.19)^{* * *}$ & -0.046 & -0.007 & 0.016 & 0.038 \\
\hline Average home to/from work travel time by bus per trip & $0.010(1.51)$ & -0.002 & -0.000 & 0.001 & 0.002 \\
\hline Respondent's rating of bus transport cost in Dubai & $-0.221(-2.92)^{* * *}$ & 0.044 & 0.007 & -0.015 & -0.036 \\
\hline $\begin{array}{l}\text { Respondent's rating of bus transport service quality in } \\
\text { Dubai }\end{array}$ & $0.078(1.04)$ & -0.016 & -0.002 & 0.005 & 0.013 \\
\hline $\begin{array}{l}\text { Respondent's willingness to use bus if near home/work } \\
\text { place }\end{array}$ & $0.320(2.23)^{* *}$ & -0.062 & -0.011 & 0.021 & 0.053 \\
\hline Respondent believe that bus is safe for children & $0.227(1.72)^{*}$ & -0.045 & -0.007 & 0.015 & 0.037 \\
\hline $\begin{array}{l}\text { Respondent believe that people need incentives to spend } \\
\text { more on public bus }\end{array}$ & $-0.129(-1.36)$ & 0.026 & 0.004 & -0.009 & -0.021 \\
\hline $\begin{array}{l}\text { Respondent is willing to use carpooling if provided by } \\
\text { RTA }\end{array}$ & $-0.127(-1.58)$ & 0.025 & 0.004 & -0.008 & -0.021 \\
\hline $\begin{array}{l}\text { Monthly fee the respondent is willing to pay for } \\
\text { carpooling }\end{array}$ & $0.002(2.12)^{* *}$ & -0.0003 & -0.0001 & 0.0001 & 0.001 \\
\hline Threshold parameter 1 & $-1.884 * * *$ & & & & \\
\hline Threshold parameter 2 & $-0.2965 * * *$ & & & & \\
\hline Threshold parameter 3 & $0.4634 * * *$ & & & & \\
\hline Predicted probabilities & & 0.2734 & 0.3747 & 0.1494 & 0.2026 \\
\hline
\end{tabular}

Log likelihood $=-1095.89$

McKelvey and Zavoina's $\mathrm{R}^{2}: 0.10$

Likelihood ratio test of zero slope coefficients $(22)=84.92 * * *$

*: Significant at the 0.10 level.

**: Significant at the 0.05 level.

***: Significant at the 0.01 level.

The result also shows that willingness to pay for the improved bus service is related to whether or not bus stations will be near to respondent's home or work place. The marginal effects for this variable are negative for the "willing to pay up to AED 2 per trip" and "willing to pay above AED 2 and up to AED 3 per trip" categories, but positive for the other willingness to pay categories. Having a bus station near home or work place increases 
the willingness probability to pay more than AED 3 per trip for using the improved public bus service. Similarly respondents who believe that bus is safe for children are willing to pay more than AED 3 per trip for using the improved public bus service than those who believe otherwise. Having a belief that bus is safe for children decreases the willingness probability to pay up to AED 2 per trip by 4.5 percentage points and increases willingness probability to pay above AED 4 per trip by 3.7 percentage points.

The marginal effects of the "monthly fee the respondent is willing to pay for carpooling" variable are negative for the first two willingness to pay categories, but positive for the other willingness to pay categories. As respondents' willingness to pay amount for carpooling (if provided by RTA) increases, the probability of being unwilling to pay "up to AED 2 per trip" and "willing to pay above AED 2 and up to AED 3 per trip" decreases, while the probability of being willing to pay a higher premium for using the improved public bus service increases.

\section{Conclusions and Recommendations}

The provision of better quality public transport service is a challenge in the UAE, as this country tries to meet the transport requirements fundamental to sustain the investment and economic as well as urban population growth exhibited over the last few years. In this regard, the UAE government strategies include increase the share of public transportation and decreasing transport by private vehicles (and hence contribute towards mitigating air and sound pollution as well as traffic congestion) through bettering public transport service quality. Such shift of demand for public transport service requires not only understanding of people's willingness to use and pay for improved public transport services but also market incentives to pull-down personal vehicle ownership demand into public transport services. This study, therefore, examines passengers' demand (willingness to use and pay) for improved public transport services.

The study uses a contingent valuation survey conducted on 852 representative sample of a cross section of UAE residents. Probit and Ordered logit models are used to analyze the survey data. Accordingly, the estimation result indicates a strong likelihood that the average UAE resident is willing to use the improved public bus service. The residents' willingness to use is determined by such factors as employment type, RTA's incentive mechanisms for using bus, proximity of bus stations to home and work places, car ownership, and children's safety for using the bus service.

The result also shows a strong likelihood that the average UAE resident is willing to pay for the improved public bus service. About 35 percent of respondents would be willing to pay a modest (AED 2 to AED 3 per trip) fee, while about 36 percent of respondents would be willing to pay more than AED 3 per trip, and about 22 percent of the respondents are willing to pay as high as more than AED 4 per trip for using the a public bus provided its service quality is improved. Broadly, several factors influence willingness to pay for improved public bus service in Dubai. Passengers are more likely to pay a higher fee (above AED 3 per trip) if they are older, UAE nationals, car owners, if the bus station is near to their home and work place, if they believe that bus is safe for children, and if they are willing to pay a higher monthly fee for carpooling (if provided by RTA). Passengers who are contented with the existing bus transportation cost are less likely to pay a higher fee (above AED 3 per trip).

Given that Government's (i.e. RTA's) motive is not purely monetary profit, understanding the maximum willingness to pay amount (and hence the consumers' surplus) for using an improved public bus service is imperative. The result suggests that there is the knowledge that residents, in general, are willing to use and pay higher fees for using public bus provided its service quality is improved. This should provide assurance to RTA who may be concerned about the potential demand for improved public bus service. In order for the UAE government to increase the share of public transportation and decrease transport by private vehicles, effort will have to continue to improve the public bus service quality. In particular, marketing of such improved service will have to consider the residents' socioeconomic and demographic as well as some travel attributes.

\section{Acknowledgments}

The release time support from the University of Dubai to the author to work on this paper is greatly acknowledged. The author would like to sincerely thank Dr. Geoffrey Gachino for his invaluable work in proof reading and editing the manuscript of this paper.

\section{References}

Carson, R. (2011). Contingent Valuation: A Comprehensive Bibliography and History. Cheltenham: Edward Elgar Publishing.

Carson, R., Flores, N., \& Meade, N. (2001). Contingent Valuation: Controversies and Evidence. Environmental and Resource Economics, 19(2), 173-210. http://dx.doi.org/10.1023/A:1011128332243 
Cranfield, J., \& Magnusson, E. (2003). Canadian consumers' Willingnessto Pay for Pesticide-Free Food Products: An Ordered Probit Analysis. International Food and Agribusiness Management Review, 6(4), 13-30.

Denant-Boemont, L., \& Petiot, R. (2003). Information value and sequential decision-makingin a transport setting: an experimental study. Transportation Research Part B, 37(4), 365-386. http://dx.doi.org/10.1016/S0191-2615(02)00018-8

Dubai at random. (2008). Random Thoughts about Life in Dubai: What's Happening with Dubai Bus Service? Retrieved from http://dubaiatrandom.blogspot.ae/2008/01/whats-happening-with-dubai-bus-service.html

Eboli, L., \& Mazzulla, G. (2008). Willingness-to-pay of public transport users for improvement in service quality. European Transport, International Journal of Transport Economics, 38, 107-118. ISTIEE, Trieste.

Freeman, A. (2003). The Measurement of Environmental and Resource Values: Theory and Methods. Resource for the Future (2nd ed.). Washington, DC.

Genanew, B., \& Schneider, F. (2009). Preference to Forms of Land Conservation Investments: The role of poverty, land tenure security, and market incentives: An Example from the Highlands of Amhara Region, Ethiopia-East Africa. Presented at the $17^{\text {th }}$ Annual Conference of the European Association of Environmental and Resource Economists (pp. 24-27). Amsterdam, the Netherlands, VrijeUniversiteit (VU University Amsterdam).

Government of Dubai. (2007). Dubai Strategic Plan 2015. Retrieved from http://www.deg.gov.ae/SiteCollectionImages/Content/pubdocs/Dubai_Strategic_Plan_2015.pdf

Greene, W. (2011). Econometric Analysis (7th ed.). Upper Saddle River: Person Education, Inc.

Hensher, D. (2006a). The Signs of the Times: Imposing a Globally Signed Condition on Willingness to Pay Distributions. Transportation, 33(3), 205-222. http://dx.doi.org/10.1007/s11116-005-2302-9

Hensher, D. (2006b). Towards a practical method to establish comparable values of travel time savings from stated choice experiments with differing design dimensions. Transportation Research Part A, 40(10), 829-840. http://dx.doi.org/10.1016/j.tra.2006.02.001

Hess, S., Bielaire, M., \& Polak, J. (2005). Estimation of value of travel-time savings using mixed logit models. Transportation Research Part A: Policy and Practice, 39(2-3), 221-236. http://dx.doi.org/10.1016/j.tra.2004.09.007

Jim, C., \& Chen, W. (2007). Consumption preferences and environmental externalities: A hedonic analysis of the housing market in Guangzhou. Geoforum, 38(2), 414-431. http://dx.doi.org/10.1016/j.geoforum.2006.10.002

Kumarage, A. (2007). Impacts of transportation infrastructure and serviceson urban poverty and land development in Colombo, Srilanka. Global Urban Development Magazine, 3(1), 1-15.

Liston-Heyes, C., \& Heyes, A. (1999). Recreational Benefits from the Dartmoor National Park. Journal of Environmental Management, 55(2), 69-80. http://dx.doi.org/10.1006/jema.1998.0244

Long, J., \& Freese, J. (2006). Regression Models for Categorical Dependent Variables Using Stata (2nd ed.). Stata Press Publisher.

McFadden, D. (1998). Measuring Willingness-to-Pay for Transportation Improvements. Theoretical Foundations of Travel Choice Modeling, 339-364. University of California Transportation Center. http://dx.doi.org/10.1016/B978-008043062-1/50016-6

Mitchell, R., \& Carson, R. (1989). Using Surveys to Value Public Goods: The Contingent Valuation Method. Resource for the future, N.W., Washington, D.C.

Murray, A., \& Wu, X. (2003). Accessibility tradeoffs in public transit planning. Journal of Geographical Systems, 5(1), 93-107. http://dx.doi.org/10.1007/s101090300105

Phanikumar, C., \& Maitra, B. (2006). Modeling Willingness-To-Pay Values For Rural Bus Attributes Under Different Trip Purposes. Journal of the Transportation Research Forum, 45(2), 31-44. http://dx.doi.org/10.5399/osu/jtrf.45.2.911

Ramanayya, V., \& Negadevara, S. (2007). Qualitative expectations of transport services and willingness-to-pay: case of KSRTC. AIMS International, 1(1), 39-52.

Samuelson, P. (1954). The pure theory of public expenditure. The Review of Economics and Statistics, 36(4), 387-389. http://dx.doi.org/10.2307/1925895 
Walton, D., Thomas, G., \& Cenek, P. (2004). Self and others' willingness to pay for improvements to the paved road surface. Transportation Research Part A: Policy and Practice, 38(7), 483-494. http://dx.doi.org/10.1016/j.tra.2004.03.004

Wattage, P. (2002). Literature review Contingent Valuation Method. Effective Management for Biodiversity Conservation in Sri Lankan Coastal Wetlands: CVM I - Literature Review, Final Report A-I.

Weldesilassie, A., Fror, O., Boelee, E., \& Dabbert, S. (2009). The Economic Value of Improved Wastewater Irrigation: A Contingent Valuation Study in Addis Ababa, Ethiopia. Journal of Agricultural and Resource Economics, 34(3), 428-449.

Zheng, L., \& Hensher, D. (2011). Crowding and public transport: A review of willingness to pay evidence and its $\begin{array}{lllll}\text { relevance in project appraisal. Transport Policy, } & \text { 18(6), }\end{array}$ http://dx.doi.org/10.1016/j.tranpol.2011.06.003

\section{Notes}

Note 1. In announcing Dubai's strategic plan 2015 on the 3rd of February 2007, His Highness Sheikh Mohammed bin Rashid Al Maktoum, UAE Vice President and Prime Minister and Ruler of Dubai stressed his vision to involve "....addressing current congestion problems, and accommodating future needs by increasing the share of public transportation and decreasing transport by private vehicles; increasing the capacity of road networks and transportation systems; securing optimal use through modern techniques, demand management, and accident and emergency management; and improving driver behavior".

Note 2. These quality improvements include: Renewal/building of all stations (with air conditioner, thin film transistor (TFT) screens, bus timings announcements, etc.). Automated vehicle management (AVM) system providing real information, Real time passenger information (RTPI) system providing up-to-date information (monitoring each vehicle) by means of electronic displays to make it possible to inform the passengers about delays or the status of interconnections they might wish to make and so on, Maintaining posted schedule time, Minimizing (10 to 15 minutes) waiting time at stations, Minimizing traveling time (e.g. by specifying routs priorily for public bus), and Providing special fuel for public buses that can cause minimal air pollution. These quality attributes are in line with RTA's plan to improve the quality of public transport in Dubai to reach the highest international standards in its services. See the 'survey design' section of this paper.

Note 3. The hedonic pricing approach (such as property value and wage model) relies on actual behavior observed in the housing market, and has been used in estimating the environmental externalities, such as air pollution, transport safety and traffic noise) (cf. Eboli and Mazzulla, 2008; Jim and Chen, 2007; and Freeman, 2003). The travel cost method is used to estimate users' benefits from visits to recreational sites (such as parks, beaches, and heritage sites) (Liston-Heyes and Heyes, 1999). Both these revealed preferences and the stated preferences are the basic approaches to non-market valuation that have been in use for decades. See Freeman, 2003; and Carson, 2011; and Carson, et al., 2001, for overviews of the theoretical and empirical issues involved.

Note 4. Total value can be decomposed into direct use value and passive use value. The former requires the agent to physically experience the commodity somehow, and any uses not requiring this direct contact are often called passive uses.

Note 5. See the review of literature on CVM by Wattage, 2002.

Note 6. The disadvantage of the follow-up approach is that it is not suitable for mail surveys because of the follow-up questions. The data used in this study is, therefore, collected through in-person interview.

Note 7. This bias occurs when a respondent does not reveal his "true" value of the service, in the hope of either a "free ride" or in order to ensure the provision of the service. Such strategic behavior in the form of free riding has long concerned economists dealing with the public good/service (cf. Samuelson, 1954).

Note 8. This is where warm glow in CV surveys might be troublesome. This bias occurs when CV survey respondents attempt to answer questions that they think will please the interviewer. They might agree (or not agree) to pay some amount when they would not do so otherwise except for the utility gain associated with telling the interviewer (Carson, et al., 2001).

Note 9. This bias occurs when initial explanation of the service or proposed scenario is not clear to the respondent. The rational for this bias is that respondents cannot have well-defined preferences in an economic sense for goods or services with which they have no direct experience. Thus ensuring that the prospective consumers understand what they are being asked to value, how it will be produced, and how it will be paid is needed in designing CV survey. 
Note 10. This bias may occur when the respondent is being confronted by a contrived, rather than actual, set of choices. Since the respondent will not have to pay the estimated value, [s] he may treat the survey casually, providing ill-considered answers.

Note 11. Relevant documents from the Road and Transport Authority (RTA) of the Emirate of Dubai and other pertinent documents have been used as secondary sources.

Note 12. Ownership of car and gender and nationality were considered to be represented in the sample.

Note 13. The questioner has been pre-tested before implementation. An important contribution of the pilot survey was to set the starting point of the bidding in the elicitation part of the questionnaire. During the pilot survey, the willingness to pay elicitation part was open-ended. The pilot survey revealed that AED 3.00 (1USD $\approx$ 3.67AED, March 20, 2013) per trip was the most frequent value, and hence this value is used as a starting point of the willingness to pay bidding game.

Note 14. Attempt was made to avoid the interviewer bias through training the enumerators to be as neutral as possible when posing the survey question. Moreover, we found no significant difference in the average willingness to pay between the respondents interviewed face-to-face and the respondents who were asked to fill their responses, sealed it and send it to our specified address.

Note 15. This random component represents the unobservable factors, such as unobservable variations in preferences, random individual behavior and measurement error.

Note 16. Threshold parameters represent points at which the change in utility is sufficiently high to permit a resident being willing to pay more for the selected service. Moreover, $-\infty=\gamma_{0}<\gamma_{1}<\ldots<\gamma_{J}$, with $\gamma_{1}$ being set equal to zero during estimation (cf. Cranfield, et al., 2003).

Note 17. The distributions of the standard normal and logistic densities are similar: both are symmetric, bell-shaped curves though the later has heavier tails than the former. Consequently, the results derived using the two models are quite similar.

Note 18. The dependent variable is respondent's willingness to pay for the improved public bus service and it takes four ordered values: 0 if "willing to pay up to AED 2 per trip", 1 if "willing to pay above AED 2 and up to AED 3 per trip", 2 if "willing to pay above AED 3 and up to AED 4 per trip", and 3 if "willing to pay above AED 4 per trip". 